\title{
Culture and Leadership: a Lewinian Perspective of Organizational Problem Solving
}

\author{
Enno Freiherr von Fircks ${ }^{1}$ D
}

Received: 23 August 2021 / Revised: 4 October 2021 / Accepted: 6 October 2021

(C) The Author(s) 2021

\begin{abstract}
Leadership is inherently social. Being grounded in the Lewinian framework of field theory, I am instancing the diverse understanding of social leadership: Uncertainty reduction, making choices, assuming responsibility, and contributing to an orchestral interplay between followers are important functions of social leadership. But this is not sufficient. Organizations are built by concrete agents with concrete needs and overreaching goals. These needs and goals structure the environment (personal culture) of various employees including the leader. Drawing on an empirical case from a bakery as well as on Lewinian cases from the past, I am showing how group atmosphere alone is not able to cover the full range of the follower's reactions: Here, we need to rely on basic concepts of culture: Employees live and work in their related life spaces. Complexity arises in organizations if the goal pursuit between followers themselves is contradictory, thus if their life spaces are a barrier for each other. The leader needs to realize here that this is not a disadvantage; his role is neither to solve these contradictions nor to present a potential solution. The leader needs to emphasize the interdependence of his followers; s/he can do so by letting them experience the issues and difficulties of the social other encountered in their respective life spaces. Here, followers are getting a glimpse into the life space (personal culture) of a colleague. Such border experiences play a key role for the following democratic exchange of how two previously contradictory life spaces are turned into conciliatory ones.
\end{abstract}

Keywords Leadership and culture $\cdot$ Interdependence $\cdot$ Field theory $\cdot$ Environmental leadership

\section{A Look in the Past: on the Roots of Leadership}

To begin with let us take a look in the past: At the heart of all the leadership studies performed by Lewin et al. (1939), we cannot ignore the overall effects of democratic leadership atmosphere versus the autocratic one revealing how leadership impacts group behavior adaptively vs. non-adaptively. "The authoritarian club members developed a

Enno Freiherr von Fircks

ennovonfircks@googlemail.com

1 Keele University, Keele, England 
pattern of aggressive domination toward one another, and their relation to the leader was one of submission or of persistent demands for attentions. The interactions in the democratic club were more spontaneous, more fact-minded, and friendly" (p. 277). In general, the results of the study show that leadership sets the condition for various group dynamics ranging from observer judgements like "dull, lifeless, submissive, repressed, and apathetic (...) [to] little smiling, joking, freedom of movement [and] freedom of initiating new projects" (Lewin et al., 1939, p. 283). For the readers, the results might seem clear, but the vast implications have been ignored already a while ago. In short, leadership remains first and foremost a social phenomenon and must not be confused with trait-like characteristics of a potential leader facing his group. "The uniqueness of a particular organization is partly due to the way in which the life space of the leader and his group is structured" (Bavelas, 1944, p. 1). Interrelated life spaces in Lewinian terms mean in this context the interdependence of a leader's person (inner core regions) and his environment with those life spaces of the group. Essentially, the life space is structured by (psychological) needs that are crucial for the goal setting and pursuing of leaders and followers. Tension is freed temporarily within the process of goal attainment or need satisfaction and set up once again a new need emerges within the life space of the respective individual. Within the Lewinian scope, tension is not freed if goal attainment is made impossible by ways of psychological or interpersonal barriers which results henceforth in confusion, frustration, and aggression (Lewin, 1926, 1935/2013, 1948/2000). Leadership is thereof a complex social field of action that needs to take into account the totality of interrelated fields. "In these terms we come close to the notion of leadership, not as a personal quality, but as an organizational function" (Bavelas, 1960, p. 494) ${ }^{1}$.

We need to stop here to look for the application of what is depicted above. Let us take a bakery for example ${ }^{2}$. The bakery is constituted of the sales room, a sitting area, the bakehouse, the breakroom, and eventually the leader's office. Every topological space is psychologically appropriated, hence structured in terms of needs and goals set by concrete persons. The counter needs to be cleaned adequately insofar as the baked goods look attractive to the customer; the sellers for example need to construct a list with the bread's ingredients because of customer specific allergies or questions; the sitting area needs to look cozy and welcoming, and the bakehouse needs to produce the baked goods. Essentially, the life spaces of the seller, the waitress, the baker as well as a cleaning man/lady are interdependent. Speaking in Lewinian terms, their goal attainment is dependent upon the goal attainment of the social other. Without any baker, there would be no baked goods for the counter; without waiter/waitress, there would be nobody to serve the customer's wishes or to deliver friendly and attentively his/her order; without a cleaning person, the chairs and tables would look like a mess at the end of the day. The interdependence is easy to be imagined within this extreme example. However, the interdependent life spaces are more heavily stressed when faced with diffuser problems. Let us look at that closer.

\footnotetext{
1 In this article, I remain first and foremost in the Lewinian tradition of understanding leadership, socially. Bavelas, Marrow, French (among others) have been all pupils of the late Lewin in his Iowa years (Marrow, 1969) consolidating Lewin's interest in action research covering areas like leadership, sustainable management change, and group dynamics within the field.

${ }^{2}$ Of course, I do not wish to compare a bakery to an educational setting. However, both are social systems, interrelated life spaces of which Lewinian theory tries to make sense of. The present article tries to understand the complexities of such a system.
} 
Now, we need to stop here again for a moment and realize the historical context in which Lewin and his colleagues developed the leadership framework I am using in this article. Developed in his late Iowa years (Marrow, 1969), Lewin expanded his democratic $<>$ autocratic research onto the business sector. He soon become friends with Alfred Marrow (Marrow, 1969) who was not only a psychological colleague but also the owner of the Harwood sewing factory where Lewin and his colleagues put their theoretical insights into practice and developed an industrial action research project (relying on Lewin's field theory). Most evidently, Harwood did profit from the newly founded research group when the factory's management decided to overtake a concurrent business, Weldon (Marrow, 1967). During that process, the management was confronted with a great percentage of absenteeism, turnover, frustration, and interpersonal problems due to a former autocratic management style that denied participation and democratic investment from their employees (Marrow, 1964). The cultural leadership framework I develop here originates from that Lewinian research that yielded into the improvement of the takeover process and that helped to democratize the enterprise's functioning (Marrow, 1964). As it becomes visible throughout the article, in our modern times, small businesses still show autocratic elements of which their leaders are sometimes unaware of. The Lewinian framework is therefore still valid in our modern times.

\section{The Function of Leadership}

Let us imagine the case that there is a sort of miscommunication in the bakery example; the bakers produce a high quantity of baked goods without talking to the sellers which products are the customer's favorites and which not. Soon, the client sitting on a table and talking to the waitress would order a piece of cake (chocolate) that was already sold out hours ago whereas there is an oversupply of marzipan cake which is the customer's least favorite. The problem in this example is that the customer is not only frustrated because he could not satisfy his need but the whole action bears symbolic meaning (von Fircks, 2021) insofar as the customer might leave the bakery while saying to a new client-in the moment of entering the bakery-do not go in there, they do not do their jobs, adequately. Need satisfaction or goal attainment as Lewin so often emphasized is always paired with some kind of experience/knowledge. The experience-be it primary or secondary by talking to a friend for example-impacts highly the need satisfaction of an individual. The bakery's adaptive interdependence is therefore not only central to the client in the here and now setting but transcends it by means of symbolic meaning for future clients. Most importantly, our little example shows crucially the basic leadership functions for the interdependence of an organization:

[P]lanning, giving information, evaluating, arbitrating, controlling, rewarding, punishing, and the like. All of these stem from the underlying idea that leadership acts are those which help the group achieve its objectives, or, as it is also put, to satisfy its needs. (...) [T] he emergence of a leader can well be accounted for on this basis. That person who can assist or facilitate the group most in reaching a satisfactory state is most likely to be regarded as the leader. (Bavelas, 1960, p. 495, author's emphasis)

Again, the organizational function of leadership becomes apparent when a problem emerges. Let us look once again at the bakery: The sellers experience day-in day-out that several customers might want to look at the breads' ingredients. Unsure about the right 
answer, they mumble something back. It becomes clear that the bakery needs to construct a list of the bread's ingredients to satisfy the demands of the customer. The leader can only assist in creating such a list as he is not serving the customer as extensively as the two sellers in the salesroom. They know their clients, they know their questions, they know their favorite breads, they know their least favorite ones, potentially their allergies and so forth. Of course, the bakers need to become involved in that process too as they produce the goods and can eventually try a new type of flour. The leader in his role cannot create that list but he can decide to launch the process of creating it. With the voice of the Lewinian scholar Bavelas (1960), "leadership consists of uncertainty reduction. The actual behavior through which this reduction is accomplished is the making of choices" (p. 495), including the way of distributing responsibility to account for the goal attainment of the follower's own action field.

Let us summarize the abovementioned: The role of leadership is inherently social; it includes the structuring of one's own life space in accordance with those of one's very followers; communication is the vital source for that insofar as the social other might become aware of one's own overreaching goals and how s/he can contribute to that or is himself/ herself instructed to work interdependently. Of course, the leader in our abovementioned example is not completely left apart within the process of creating a list with the bread's ingredients. He would be, for example, responsible for the pricing of a newly created bread in a way that it respects his economic needs/interests. This is what Bavelas emphasizes again and again (1960); in such an interdependent example, everybody is in a certain way leader and follower not simultaneously but sequentially.

\section{The Function of Culture}

Now that we have briefly clarified what leadership is about while regrouping it into the original Lewinian framework, we must clarify how culture fits into all of that. There is an interesting paragraph in the pioneer work of Lewin et al. (1939) instancing how culture might impact leadership atmospheres: In the original democratic, autocratic, and laissezfaire experiment, Lewin and his team asked the boys if they liked their leaders. Here are the results:

With surprising unanimity the boys agreed in a relative dislike for their autocratic leader regardless of his individual personality. Nineteen of the 20 boys liked their leader in democracy better than their leader in autocracy. The twentieth boy, as it happened, was the son of an army officer (the only one in the group), and consciously put a high value upon strict discipline. As he expressed it, the autocratic leader 'was the strictest, and I like that a lot.' The other two leaders 'let us go ahead and fight, and that isn't good'. (Lewin et al., 1939, p. 284, author's emphasis).

Here is the link to culture. Democratic leadership did not satisfy all of the young boys, and the deviation of one young fellow appreciating the autocratic one hides itself within his personal culture. Lewin and his colleagues intuitively use the right terms for describing what happens in the interview. The young fellow values differently than his peers. The experiment bears different symbolic meaning for him. It is this symbolic meaning that indicates how personal culture impacts our very own meaning making in the here and now setting (Toomela, 2021) and how it triggers action, here welcoming the autocratic leadership style as well as not feeling at ease within the democratic leadership group. Lewin 
Fig. 1 Different symbolic actions to reach the goal of being polite. The goal (G) of being polite can be reached by different paths depending on the symbolic value capacities of the child (C). Note the dynamic, situatedness of the field. A person immerged in a book is not likely to be talked to as the disturbance might be interpreted as impolite

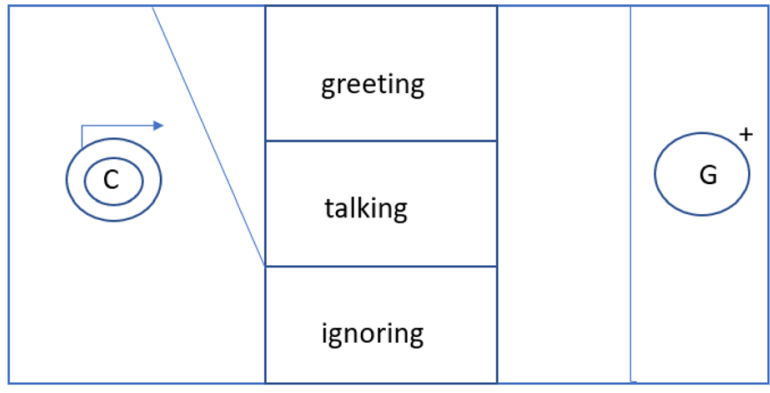

(1948/2000) as well as the Swiss cultural psychologist Boesch ${ }^{3}$ (1991) do not get tired of instancing the particular role of our family in guiding our action fields from very early on. Of course, the child at the very beginning of his life needs to rely on his parents for his need satisfaction (biological as well as social) but continues to rely on it until puberty where he might develop his own higher psychological needs as well as overreaching goals.

Let us take a simple example to illustrate that: A child grows up in a small town; his parents teach him to greet his neighbors on the street as this is a sign of being polite and friendly towards the people with whom you live (see Fig. $1^{4}$ ). Once spotting a person not greeting him back, he might interpret that action as rude, arrogant, or impolite. However, the interpretation, the symbolic value of that action, here the non-greeting, has implications for the subsequent child's action. The child might ignore that person for the next four weeks or might gossip with his parents about the reasons why this stranger did not greet back.

In all these imaginary cases, the child is in accordance with the symbolic interpretation of his parents creating a cultural environment (Toomela, 2021) with clear stimuli how to deal with people not greeting back. In short, culture is an action field with concrete symbolic implications of how to interpret a certain event. These symbolic interpretations create then an artificial environment ${ }^{5}$ for the person consolidating the symbolic meaning of the event. When the child enters puberty, he might ask himself if non-greeting is really a sign of arrogance or impoliteness and he might arrive at the conclusion that non-greeting is definitely not a sign for being rude or arrogant but maybe for being tired or even rebellious. In the course of the latter, the child might even want to befriend that person. But essentially

\footnotetext{
${ }^{3}$ Boesch is clearly a Lewinian scholar; his concept of action field goes back to Lewin's life space. There are no major differences in Lewin's life space and Boesch's action field. That is why I use the terms interchangeably. Where Boesch speaks of goals and barriers (1991), Lewin speaks of quasi-needs and barriers (1948/2000). However, both speak of valences. This justifies the interchangeable use of action field and life space.

4 The idea for the following figures goes back to the leadership study of Lewin and his colleagues (1939) who were able to show complex intergroup dynamics by means of topological representations.

5 Artificial environment means in lose tradition of Toomela (2021), the appropriation of the natural environment with all of its objects in an interpretational process. The greeting is first and foremost present in the natural environment of a person; people are waving to each other, but in a second step, the waving becomes greeting, and in a third, the non-waving becomes interpreted as impolite and arrogant. Certain environmental givens are thus appropriated differently; they get loaded with some specific personal meaning; they become a sign which unfolds afterwards consequences for the behavior of a concrete person. Thus, natural environment becomes an artificial environment through sign-making processes and their valences (see also Lang, 1993)
} 
Fig. 2 Different symbolic actions to reach the goal of being polite as a function of pressure set up by parental action fields. The goal of being polite can be reached by different paths. However, the symbolic action of greeting is not performed freely by the child but by his parent's social pressure and their action fields

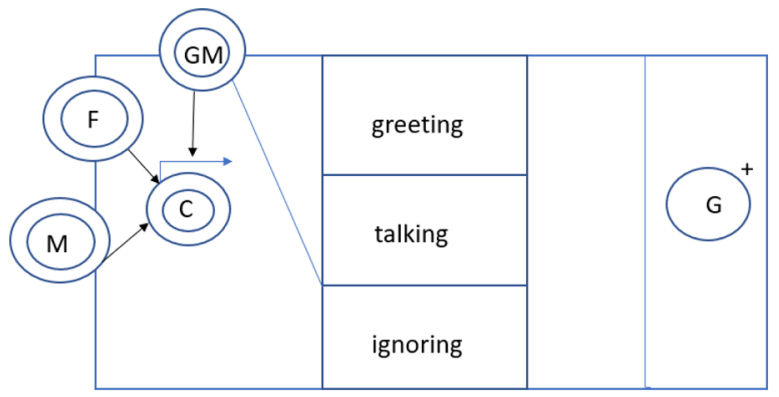

before puberty, he adopts the action field of his parents and therefore is in line with the symbolic valuing of the non-greeting event. Most importantly, his parents $(\mathrm{F}=$ father, $\mathrm{M}=$ mother, $\mathrm{GM}=$ grandmother) put up a normative pressure (Boesch, 2002; Lewin, 1948/2000) to be in line with the parent's interpretation (see Fig. 2).

Something similar might have happened in the story of the young fellow appreciating the autocratic leadership style. Being 10 years old, his action field is still highly structured by his parents, when to eat, when to do homework, how to do sports, how to behave in public, how to talk to family friends, how to behave in school, what to think about discipline, how to become a successful member of society, what to think about the parent's job, and most importantly what order means. Still too young to lay out his very own needs and goals, the boy accepts mostly the actions of his parents with all the symbolic implications that come with it. Interestingly, he welcomes the autocratic leadership style for creating order and justice, see Fig. 3 (they let us go ahead and fight, and that isn't good).

\section{Topology as Scaffolding to Understand Leadership Issues}

By now, we have elaborated the terms culture and leadership. Let us take our theory one step further and apply that to our bakery case. The bakery wants to construct a list with all of the bread's ingredients. However, there are different interests, needs, and goals

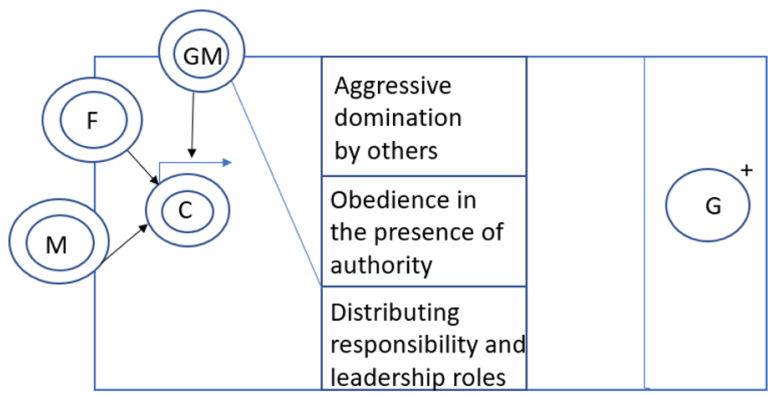

Fig. 3 Different symbolic actions to reach the goal of creating order (after Lewin et al., 1939). The goal can be reached by different paths depending on the symbolic value capacities of the child: Most importantly, the symbolic action of aggressive domination by others or obedience, to reach the goal of order, needs to be understood by taking into account the pressure of the child's parental action fields 


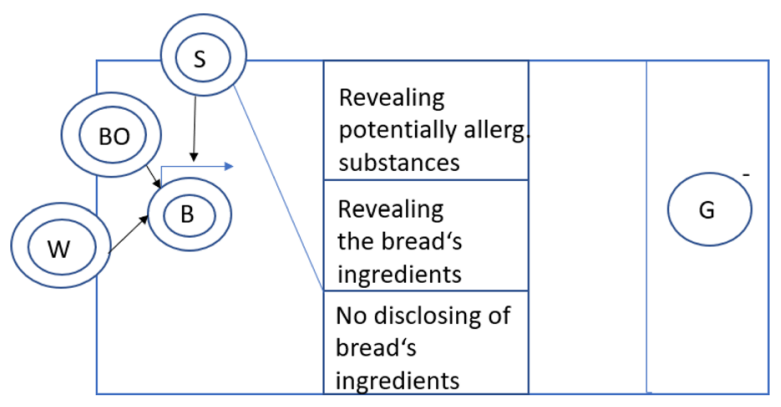

Fig. 4 Different symbolic actions to avoid potential copies of the breads. The goal of keeping the ingredient's secret and to maintain social prestige is central for the baker (B); the boss is likely to share that perspective to maintain his economic interest; he is therefore not as distant as the seller (S) or the waiter (W) who both belong to the salesroom area and are not likely to experience the fears of the bakers. S and W both have own interests but are too distant to exert a particularly high influence on the baker

concerning such a list. The boss/leader wants to assure himself that the prices are raised of two particular breads because of the use of a costly type of flour. The sellers want to order the list insofar as the best sold breads are at the head of the list and the least sold ones at the bottom in order to have a courteous and fast service for the customer. The bakers do fear that other bakeries might look up the ingredients or that several customers want to try out the bread by themselves once they know the exact ingredients. Therefore, they hesitate in providing the right ingredients to the sellers who are co-constructing the list. The waiter/ waitress wishes to have a small handy copy for himself/herself once a client asks him/her for particular ingredients. So, here we have multiple agents in their multiple action fields structured by their overreaching goals that emerge in their specific relation with their workrelated environment. From the example, it becomes clear that all the actors are interdependent in their action fields. Let us look at the graphic representations of their life spaces in order to solve the problem jointly.

Let us start with the baker (see Fig. 4): As we see in our topological representation, the boss and the baker are more interdependent than the baker and the other employees. This is by no means a coincidence. First, the boss is also a baker and is therefore more able to feel into our present baker fearing the disclosure of the bread's ingredients. He works more closely with them than, for example, with the sellers or the waiters; he therefore shares bigger parts of his/her action field and is also more likely to impact the baker in his choice of how to disclose particular ingredients. Moreover, the baker's interest of not disclosing the ingredients is especially close to the boss' interest of maintaining his economic interests, so that the boss is more likely to share the action field of the baker.

However, the boss is fully free in cooperating with the baker to maintain his economic interests. But that does not mean that there is no pressure exerted by his other employees. They too have interests and goals that are important to structure their work-related environments. Let us look at the topological representation of the seller (see Fig. 5):

The seller is highly interdependent with the waiter/waitress as their interests almost fully converge. The waiter/waitress just wishes to have a modified short list that fits into his/her pocket. However, the main goal of serving the customer adequately insofar as they can answer ingredient specific questions is similar. Both share each other's action fields, and both exert a specific influence on the boss. They might even verbalize a statement like 
Fig. 5 Different symbolic actions to re-gain high social prestige. The seller and waiter are close to each other as their needs overlap due to similar environmental demands. The baker is too distant to experience the seriousness of their conflict. W and S are both exerting pressure on their boss as they want to master their environmental demands

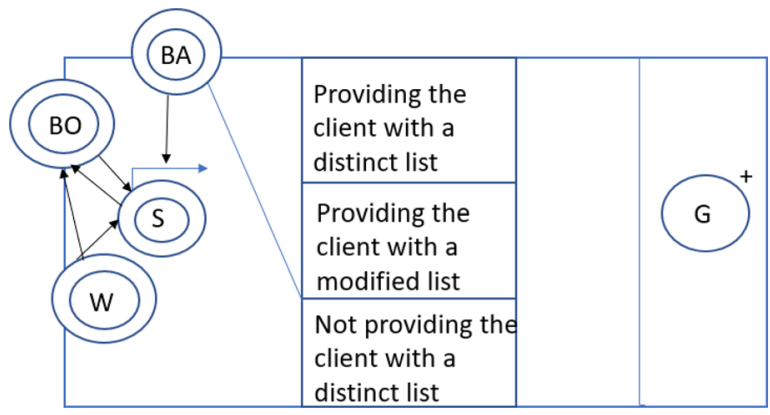

without such a list I would not be able to do my job or something similar like The client might think I do not know my job ${ }^{6}$. So, the list is polyvalent in terms of the seller's goals: It helps to bring order in the always dynamic environment of the bakery, but it is also important for the seller's prestige. The same accounts for the waiter/waitress. The list becomes therefore an important symbolic tool for the mastery of one's job (environment) ${ }^{7}$. Therefore, it is not a surprise that both seller and waiter/waitress are exerting high pressure on the action field of the boss. But where is culture in our example? The answer is simple: The seller's and waiter's environment are structured by goals and needs. However, these goals are formed within a particular environment: The mastery goal of dealing with customerspecific questions professionally emerges only because there is an environmental demand (e.g., from a customer) that challenges the prestige of the seller's job. Something similar accounts for the baker; the goal of being cautious with the bread's ingredients emerges because the bakers might have experienced that their recipes were stolen in the past. In both jobs, there are henceforth environmental demands that need to be answered in terms of the employee's action; both demands differ as their (cultural) environment differs.

Complexity arises in organizations because the action fields of various employees are not to be understood in an isolated but in an interdependent way. A potential goal attainment for one employee might threaten the goal attainment of another; hence, a compromise is needed. In that compromise, both actors need their intentions to be realized insofar as the goal attainment of one actor does not threaten the goal attainment of the other anymore. In our example, this would mean the following: The seller and the baker would agree on creating a list. However, that list does not reveal all of the bread's ingredients as well as their quantity but only allergic substances. Moreover, if a client wants to know more than that, there is an agreement settled that the sellers are able to consult a baker who comes at the counter answering the customer's question. In this way, the seller's prestige (status) is not at stake. After creating a manuscript of such a list, the boss is screening the document and is responsible for the pricing. Here, he can account for his economic interests and decide if the breads' prices need to be raised or not. Communication we mentioned above is the vital

\footnotetext{
6 The symbolic mastery of one's job is especially important in our modern age as we live in a time where we can easily write reviews on the internet and share our experience with a wide range of different people. Employees and bosses not handling the work-related demands of their life spaces appropriately risk a bad reputation in the long run.

7 This dynamic and its implications for leadership have been described elsewhere (von Fircks, 2021). Elaborating on that is beyond the scope of the present article. For now, it is sufficient to know that the case is an empirical example with the exception of the waiter's role who has been additionally added to the example in order to make the case more complex.
} 
source for making life spaces compatible; this must include a concrete exchange about the environmental demands - and barriers - of each employee that is relevant for the performance of a specific task or service (Sherif, 1968).

\section{Approaching Culture and Leadership}

What is the benefit now when considering leadership and culture together? How do practitioners and researchers profit from such an approximation. Again, the answer is simple. But we need to face its vast implications. What we have depicted above in our topological representations is highly transparent: The social other who is always present in the periphery of our very own action field needs to get a glimpse into our (cultural) environment and its demands. Here, s/he might experience our difficulties, problems, and how we want to get ahead of those by structuring our environment differently, for example, by means of tools. Here, the social other would get a glimpse into our action field as well as its underlying structure based on our personal goals. He would dive deep into our own personal culture. Here, experiencing what we fear and what we want to approach is the crucial task in order to establish cooperation. And this is the task of the leader. This Lewinian idea of expanding life spaces and making them transparent for the social other is quite different from leadership as supervision where pushing the employee towards organizational goals is the primary mechanism regardless their environmental demands. Here, goals are superimposed onto the employee that might not be compatible with the life space of the employees, thus with their work-related demands. This creates then an estrangement between leader and employee as the leader tries here to set up goals for the employee that are not pivotal to him and his work. Comparing this cultural way of leadership to leadership as supervision is a matter of a democratic bottom-up approach versus an autocratic top-down one. ${ }^{8}$

\section{Examples from the Past}

This is exactly what Lewin and Mead did (Lewin, 1943; Marrow, 1969; Mead, 1943) for changing food habits during wartime. They both compared the effect of a lecture performed on housewives versus a democratic discussion of the problem at stake as well as its potential solutions. During the democratic setting, the participants were able to experience the problem by themselves; they were seeing that something needed to be done on their parts to help their country during wartime. They formulated thus a problem they have started to see. This resulted in a free discussion of how to use alternative meat (liver among others) and in a democratic vote of trying out an eventual recipe. This was the beginning of the group decision concept (Marrow, 1969). The results in comparison to the lecture group

\footnotetext{
${ }^{8}$ During the review process, important questions were raised concerning the role of the leader. Is an unchosen leader a democratic one? The answer is negative. But this does not mean that he cannot act democratically. Even if he is an unchosen one-not elected-he can be attuned to the very needs of his employees that emerge in the relationship to their cultural environment and try to structure the action fields insofar as they are not negatively but positively interdependent. As in the classic Lewinian study (Lewin et al., 1939), the democratic leader is also unchosen but acts democratically insofar as the needs, goals, and interest of his pupils are in the foreground of his actions. This also means that the employees are fine if the leader makes a final decision as they know that they have guided it semiotically.
} 
(non-group decision) were breathtaking and showed how change is facilitated by a group experiencing and appropriating a problem and trying to solve it by their own means.

Something similar is accounted for in a study of Marrow and French (1945) changing a stereotype in industry: Simple arguments from a distinguished psychologist explaining that women over 30 perform as equally good as women under 30 "proved to be of no avail" (p. 34). A management top group needed to do research on their own, so they defined criteria and gathered data with the surprising results how efficient women over 30 have been for the company: "[The group] were excited and pleased at having participated in this important discovery which had become their own" (Marrow \& French, 1945, p. 35). However, the staff was still rigidly opposing the finding because they did not believe their facts to be true even if older workers were present in its unit. Once again, group decision was needed to challenge an obsolete attitude: "Group decisions were reached recommending that an experiment be made in the training of older workers. In this way the idea of hiring older women workers was gradually established. Only with this group shift in attitude did the new policy became a reality" (p. 36).

Again, Lewinian scholars such as Marrow $(1957,1967)$ have an easy but far-reaching explanation for that. In such a discussive group meeting, a problem becomes not somebody's problem but the group's one. A problem becomes appropriated insofar as it is now our problem with all the implications. The objective quality of the problem turns into subjective connotations (Boesch, 1991) that need to be addressed by the group. Now, the problem is among the group, and it needs to be accounted for. Turning back to our bakery example my problem as seller becomes also your problem as boss; my goal becomes your goal. If I lose prestige in face of the customer, you lose your face too. Therefore, we need to work together; therefore, we need to get ahead of our problem, jointly. The topological representations of the interrelated action fields (life spaces) shows that highly illustrative. ${ }^{9}$

\section{Understanding Cultural Leadership}

Again, this has far-reaching implications: Interdependence is not the final solution but is to start with. Interdependence is an appeal for leaders to make it possible that they themselves as well as their employees might go into the cultural environment of the social other getting a glimpse into their life space including all their problems, issues, and difficulties as well as their personal goals. Once the employees face this interdependence, once they experience that their goals depend on the goals of the social other, they are transformed and cooperation between them is facilitated. Marrow and French (1945) explain that in the following terms: "Thus, through a process of guided experiences which are equally his own, a person may be reoriented so that he gradually takes on within himself the attitudes which he would not accept from others" (p. 37). A single problem becomes the group's problem and

\footnotetext{
${ }^{9}$ One of the reviewers mentioned an important aspect: Is the set up of such an understanding of leadership manipulative as it is just another tool to enhance the sales numbers through a democratic working atmosphere where the employees believe they could equally contribute? Of course, a democratic approach is more effective (Marrow, 1957) than, for example, an autocratic one, but this is not an end in itself. The project that I outline here in tradition of Lewin believes that the workplace is more than just a place to earn money. It is a place of interaction between human beings with their unique pasts and futures; it is a place full of personal meaning that needs to be appropriated by the employees and the boss, likewise. It is a place of integration and community, and it would not work if money was the only interest between the members of the enterprise. I understand the workplace as a binding institution (see also Scruton, 2015).
} 
Fig. 6 The role of the leader (L). Interdependence is an appeal for the leader to make his employees experience the action field of the other in order to stimulate a potential convergence of goals. This is argued to be a key factor in establishing sustainable organizational change

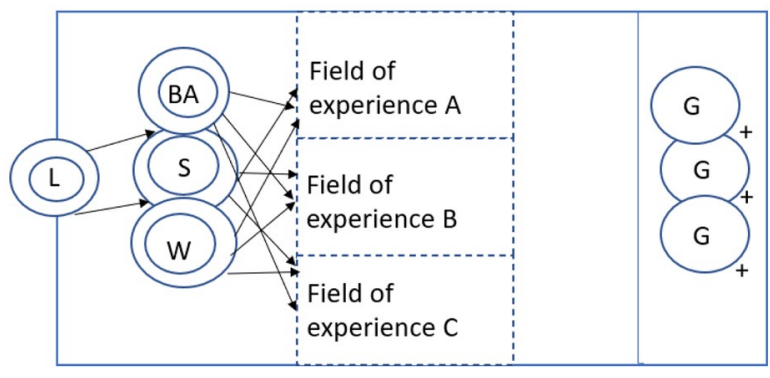

the problem per se can be faced from many different directions. Of course, this might be problematic as there are multiple perspective and interests which might be contradictive in the beginning but uniting them within one solution (such as in the list) makes sustainable changes possible, in the long run.

What is the role of the leader, now? Bavelas (1960) said it is uncertainty reduction. But this is not enough. Marrow (1957) explains good leadership is "leadership that makes the most of [an] orchestral dynamic" (p. 78). But this is not enough. And Lewin explains in his action research that believing facts need to be substituted by discovering them by own means (1948/2000). Again, this is not enough, either. In my opinion, leadership is to make the employee experiencing his very own interdependence with the social other(s). This comes close to an expansion of one's own life space. And it embraces all the three definitions depicted above. The definition sounds simple at first, but its topological representation reveals its difficulties (see Fig. 6). The leader's role is to emphasize the intersection of his employee's action fields and his appeal to not only facing but to experiencing them. Consequently, the different fields of experiences are permeable. Of course, the baker is closer to his field of experience (A) but that does not mean that he cannot enter the field of experience B or C. The same accounts for the other employees. By the leader's emphasis of the interdependent action fields and his offer to experience them individually, the employees themselves will realize that their goals are interdependent too. This realization will transform the whole realm of cooperation between the employees themselves. And this means in a second step uncertainty reduction; it means orchestral dynamic, and it means experiencing the variety of facts depending on different fields of experiences. And the readers will be surprised because this is close to the goals of cultural psychology (Boesch, 1991; Valsiner, 2007, 2014).

\section{Culture and Leadership on the Way Towards Symbiosis}

Culture and leadership we have seen are not only closely intertwined one with the other; they are interdependent. To speak of an approximation is not enough; it is a symbiosis. Why?

A leader needs to take into account the unique functioning of his organization. This functioning is constituted by his employees with their various life spaces (action fields) that are structured by needs and overreaching goals. Complexity arises for the leader because of the interrelatedness of his employee's life spaces: Universal recipes of leadership are therefore utopic because they ignore the different fields of experiences of the employees. Characterological presuppositions are also of no concrete help in that context, and we can henceforth disregard them, completely. 
The needs and goals are not only structured in a personological way but are formed within the concrete experienced (cultural) environment of the employee. The environment sets up specific demands for the employee's job and the employee needs to get ahead of these. This turns into a different structuring of the employee's action field. Needs and goals always emerge at the intersection of a person facing his environment.

Barriers can emerge within these action fields that make goal attainment difficult. Especially complex are interpersonal barriers because of supposedly contradicting goals of employees in one organization. The life space of one employee appears then as a barrier in the life space of another. If the barrier cannot be removed, the different employees implied might reply with confusion, frustration, and aggression (Lewin, 1935/2013, 1948/2000) towards each other or towards the boss (Lewin et al., 1939). Uncertainty arises, and it needs to be reduced. Here, the leader enters the stage. He needs to analyze if there are opportunities of uniting the goals rather than to let them remain contradictory. He needs to see where the employees might develop common goals and interest while maintaining his very own needs (the boss at the end of the day is also an employee of his own enterprise).

However, he cannot do this job for his employees (von Fircks, 2021); they need to experience by themselves that their goals are not as contradictory as it seems, that modified goals can be worked out jointly, that their goal attainment depends highly on the social other, and that one employee cannot satisfy his need in complete ignorance of the other. Interdependence is not a magically explanatory formula but is an appeal for the leader to let the employees experience the life space of the other. A baker might be called into the salesroom if a client comes in and wants to know the ingredients of a particular bread. Here, he can experience the pressure (tension) such a demand imposes upon the seller and the threat to his social prestige, and then, he might feel the need himself to reveal certain ingredients of his products. The leader needs to facilitate such border experiences where the social other gets a glimpse into the life space of his colleague, thus into his personal work culture.

Topological representations of various employees help us to know where needs and goals might converge and where others diverge; here, a leader can gain knowledge of where to intervene first. The seller's and waiter's action fields are starkly overlapping, and their interest are converging to a large degree; they already have a distinct glimpse into the other's workspace. Baker and seller however are not only geographically more distant but also psychologically; they do not only work in different rooms, but their interest and goals are also in supposing contradiction. This psychological distance-which is a distance towards the social other's field of experience-needs to be accounted for; it needs to be shortened; they need to be approached; they need to experience each other's workspace: An intervention is more likely to be beneficial between them and their related action fields. Topology informs about that distance and shows where interdependence needs to be made more transparent in order to stimulate high cooperation.

In the end, a leader accounting for the interdependent action fields of his employees is accounting for their personal culture in the realm of collective culture. This frees unknown potential in the whole organization. Culture and leadership are henceforth in a worthwhile symbiosis. The present article sets the seeds for that.

Acknowledgements I want to thank Jaan Valsiner for showing me the value of cultural psychology and helping me to vigorously revise my manuscripts. 


\section{Declarations}

Ethical Approval The article does not contain any studies with human participants performed by the author. It only includes personal observations at work.

Conflict of Interest The author declares no competing interests.

Open Access This article is licensed under a Creative Commons Attribution 4.0 International License, which permits use, sharing, adaptation, distribution and reproduction in any medium or format, as long as you give appropriate credit to the original author(s) and the source, provide a link to the Creative Commons licence, and indicate if changes were made. The images or other third party material in this article are included in the article's Creative Commons licence, unless indicated otherwise in a credit line to the material. If material is not included in the article's Creative Commons licence and your intended use is not permitted by statutory regulation or exceeds the permitted use, you will need to obtain permission directly from the copyright holder. To view a copy of this licence, visit http://creativecommons.org/licenses/by/4.0/.

\section{References}

Bavelas, A. (1944). An analysis of a situation preliminary to leadership training. Journal of Educational Sociology, 17(7), 426. https://doi.org/10.2307/2262552

Bavelas, A. (1960). Leadership: man and function. Administrative Science Quarterly, 4(4), 491. https://doi. org/10.2307/2390770

Boesch, E. E. (1991). Symbolic action theory and cultural psychology. New York, NY: Springer New York.

Boesch, E. E. (2002). Genese der subjektiven Kultur [Genesis of subjective culture]. In M. HildebrandNilshon, C.-H. Kim, \& D. Papadopoulos (Eds.), Kultur (in) der Psychologie: Über das Abenteuer des Kulturbegriffs in der psychologischen Theorienbildung (pp. 67-95). Heidelberg, Germany: Asanger.

Lang, A. (1993). Non-Cartesian artefacts in dwelling activities: step towards a semiotic ecology. Schweizerische Zeitschrift Für Psychologie, 52(2), 138-147. Retrieved from http://www.langpapers.org/pap2/ 1993-01noncartesartefact.htm

Lewin, K. (1926). Vorsatz. Wille und Bedürfnis: Mit Vorbemerkungen über die psychischen Kräfte und Energien und die Struktur der Seele [Purpose, will and need: With a preliminary remark about the psychological powers and energies and the structure of the mind]. Springer. https://doi.org/10.1007/ 978-3-642-50826-4

Lewin, K. (1943). The relative effectiveness of a lecture method and a method of group decision for changing food habits. National Research Council, 1943, Washington, D.C.

Lewin, K. (2000). Resolving social conflicts: field theory in social science. American Psychological Association. https://doi.org/10.1037/10269-000.(Originalworkpublished1948.)

Lewin, K. (2013). A dynamic theory of personality: selected papers (D. K. Adams \& K. E. Zener, Trans.). [Alcester, Eng.]: [Read Books]. (Original work published 1935.)

Lewin, K., Lippitt, R., \& White, R. K. (1939). Patterns of aggressive behavior in experimentally created "social climates." The Journal of Social Psychology, 10(2), 269-299. https://doi.org/10.1080/00224545.1939. 9713366

Marrow, A. J. (1957). Making management human. McGraw-Hill Book Company.

Marrow, A. J. (1964). Risks and uncertainties in action research. Journal of Social Issues, 20(3), 5-20.

Marrow, A. J. (1967). The Harwood organization. In A. J. Marrow, D. G. Bowers, \& S. E. Seashore (Eds.), Management by Participation (pp. 64-76). Harper \& Row.

Marrow, A. J. (1969). The practical theorist; the life and work of Kurt Lewin. Basic Books.

Marrow, A. J., \& French, J. R. P. (1945). Changing a stereotype in industry. Journal of Social Issues, 1(3), 33-37. https://doi.org/10.1111/j.1540-4560.1945.tb02691.x

Mead, M. (1943). The factor of food habits. The Annals of the American Academy of Political and Social Science, 225(1), 136-141. https://doi.org/10.1177/000271624322500144

Sherif, M. (1968). If the social scientist is to be more than a mere technician. Journal of Social Issues, 24(1), 41-61. https://doi.org/10.1111/j.1540-4560.1968.tb01468.x

Scruton, R. (2015). How to be a conservative (Paperback). Bloomsbury Continuum.

Toomela, A. (2021). Culture, speech and myself. Porcos ante Margaritas.

Valsiner, J. (2007). Culture in minds and societies: foundations of cultural psychology. SAGE Publications.

Valsiner, J. (2014). An invitation to cultural psychology. Los Angeles: SAGE. 
von Fircks, E. F. (2021). Cultural Resources for Leadership: When a Banana is More than a Banana. Human Arenas, 1-18. https://doi.org/10.1007/s42087-021-00231-0

Publisher's Note Springer Nature remains neutral with regard to jurisdictional claims in published maps and institutional affiliations. 